\title{
Splenic function in alcoholic liver disease
}

\author{
A F Muller, P J Toghill
}

\begin{abstract}
Splenic function was assessed in $\mathbf{4 2}$ patients with alcoholic liver disease by counting the percentage of erythrocytes with indentations or pits, seen by differential interference contrast microscopy. These pits represent cellular debris normally removed by the spleen. The findings were compared with 42 age and sex matched controls. Mean (SEM) pitted red cell counts in the patients was $2 \cdot 7(0.4) \%$ and in the controls $0.7(0.07) \%(p<0.001)$. In all of the eight reformed drinkers (five with biopsy proven cirrhosis), cell counts were normal. Six patients with alcoholic liver disease had had serious infections within the past year. Of these, one had had a recent pneumococcal pneumonia and another of the patients died from overwhelming pneumococcal septicaemia. Both of these patients had evidence of functional hyposplenism as judged by high pitted erythrocyte counts. A total of 18 patients were considered to have pitted red cell counts above the normal, and $\mathbf{1 1}$ of these had proven cirrhosis and/or gross ascites. This study is the first to show the presence of functional hyposplenism in alcoholic liver disease and provides further evidence of the predisposition that these patients have to infection. At present, it is unclear whether the hyposplenism is a direct toxic effect of alcohol or the result of cirrhosis; further studies are warranted.

(Gut 1992; 33: 1386-1389)
\end{abstract}

Functional hyposplenism - that is, reduced splenic function in the presence of the spleen is recognised to occur in a number of conditions including inflammatory bowel disease, ${ }^{1-4}$ coeliac disease, ${ }^{5-8}$ sickle cell anaemia, ${ }^{9}$ systemic lupus erythematosus, ${ }^{10}$ thyrotoxicosis, ${ }^{11}$ amyloid, ${ }^{12}$ and in old age. ${ }^{13}$ Such individuals, as in patients who have undergone splenectomy are predisposed to infections and overwhelming sepsis. Severe hyposplenism, splenectomy or splenic atrophy may be reflected by the presence in the peripheral blood film of Howell Jolly bodies, acanthocytes and target cells. Lesser degrees of hyposplenism can be detected by other techniques including the clearance of isotopically labelled heated erythrocytes ${ }^{14}$ or differential interference contrast microscopy. In the latter technique, splenic function is assessed by counting the percentage of erythrocytes with indentations or pits normally removed by the spleen. Electron microscopy has shown these pits to be vacuoles containing ferritin, haemoglobin and mitochondrial remnants. ${ }^{15}$ The technique is easier, quicker and more convenient than the clearance of isotopically labelled red cells. It has been shown to correlate well with the assessment of splenic function by other methods in patients with treated adult coeliac disease ${ }^{6}$ and in such cases there is a correlation between splenic function and splenic volume computed from scintiscans after injection of radiolabelled heat damaged red cells or ${ }^{99} \mathrm{~m} \mathrm{Tc}$ labelled sulphur colloid. There is, however, a reversible component to splenic hypofunction that is unrelated to changes in spleen size in both untreated coeliac disease ${ }^{16}{ }^{17}$ or active inflammatory bowel disease ${ }^{318}$ and this may also apply in alcoholic liver disease. In addition, functional hyposplenism may occur in the presence of 'haematological' hypersplenism and/or splenomegaly, the so called ineffective splenic mass described by Steinberg. ${ }^{19}$

Patients with liver disease may be susceptible to infection, particularly when this is secondary to alcohol abuse. In this group there is often impairment of cellular and humoral defences against infection ${ }^{20}$ but there is little information on splenic function. The aim of the present study was therefore to assess splenic function in chronic alcoholics, and to see whether functional hyposplenism might be a contributory factor in their predisposition to infection.

\section{Methods}

\section{PATIENTS}

Forty two patients with alcohol induced liver disease were studied with a mean age of 51 years (range 30-78, 14 women). Fifteen patients had biopsy proven cirrhosis and two had alcoholic hepatitis and fatty liver. Seventeen patients had gross abdominal ascites requiring diuretic therapy and/or abdominal paracentesis. Those patients who had not had liver biopsies had had significantly abnormal liver function tests and/or ultrasound or isotopic scanning evidence of liver disease. Eight patients were 'reformed' drinkers having abstained from alcohol for a duration ranging from two months to several years and five of this group had biopsy proven cirrhosis.

Six patients were found from their medical records to have had serious infections either during the current admission or within the previous two years while drinking heavily. One had had pneumoccocal pneumonia and another pneumococcal septicaemia (this patient subsequently died). One patient had recently finished a course of treatment for pulmonary tuberculosis. All patients with abdominal ascites underwent diagnostic paracententesis. The patient group was compared with results from 42 age ( \pm two years) and sex matched controls. Controls were drawn from either members of staff or ward patients who had suffered a myocardial infarction. All subjects gave informed consent. Patients or controls with a history of diseases in which hyposplenism has been reported were 
TABLE Haematochemical and clinical parameters in the 18 patients with high pitted red cell counts

\begin{tabular}{|c|c|c|c|c|c|c|c|c|c|c|c|c|}
\hline$P t$ & $\begin{array}{l}\text { Age } \\
\text { (years) }\end{array}$ & $\begin{array}{l}\text { Pit } \\
\text { count } \\
(\%)\end{array}$ & $\begin{array}{l}H b \\
(g / d l)\end{array}$ & $\underset{(f)}{M C V}$ & $W B C$ & Plts & Film & $G G T$ & Ascites & Splenomegaly & $\begin{array}{l}\text { Liver } \\
\text { biopsy }\end{array}$ & Infections \\
\hline 1 & $49 \mathrm{M}$ & $14 \cdot 8$ & $15 \cdot 2$ & 109 & $8 \cdot 7$ & 246 & - & 287 & - & - & - & - \\
\hline 2 & $52 \mathrm{M}$ & $10 \cdot 4$ & $14 \cdot 4$ & 105 & $13 \cdot 1$ & 152 & - & 504 & - & - & & \\
\hline 3 & $47 \mathrm{~F}$ & $7 \cdot 2$ & $11 \cdot 6$ & 109 & $8 \cdot 4$ & 180 & TC & 1917 & + & - & Cirrhosis & Klebsiella UTI \\
\hline 4 & $54 \mathrm{~F}$ & $6 \cdot 2$ & $14 \cdot 2$ & 103 & $5 \cdot 6$ & 76 & TC & 240 & + & - & & \\
\hline 5 & $61 \mathrm{~F}$ & $6 \cdot 1$ & 10.6 & 96 & $3 \cdot 8$ & 101 & L shift & 390 & + & - & Hepatitis & Pneumococcal septicaemia \\
\hline 6 & $60 \mathrm{M}$ & $5 \cdot 1$ & $10 \cdot 1$ & 100 & $3 \cdot 1$ & 70 & TC & 17 & + & + & Cirrhosis & \\
\hline 7 & $47 \mathrm{M}$ & 4.9 & 11.6 & 101 & 7.9 & 166 & TC & 356 & + & - & Cirrhosis & Pneumococcal pneumonia \\
\hline 8 & $31 \mathrm{~F}$ & $4 \cdot 6$ & $15 \cdot 1$ & 99 & $11 \cdot 4$ & 248 & - & 328 & + & - & & - \\
\hline 9 & $57 \mathrm{M}$ & $4 \cdot 1$ & 10.6 & 103 & $17 \cdot 5$ & 330 & - & 526 & + & - & Cirrhosis & - \\
\hline 10 & $44 \mathrm{~F}$ & $4 \cdot 0$ & $13 \cdot 3$ & 97 & $10 \cdot 1$ & 168 & - & 51 & + & - & - & - \\
\hline 11 & $33 \mathrm{~F}$ & 3.4 & $14 \cdot 2$ & 99 & 8.6 & 192 & - & 51 & - & - & - & - \\
\hline 12 & $56 \mathrm{M}$ & $3 \cdot 3$ & 16.0 & 99 & $7 \cdot 8$ & 88 & - & 1214 & + & - & Hepatitis & - \\
\hline 13 & $33 \mathrm{~F}$ & $3 \cdot 0$ & 13.4 & 112 & 10.9 & 430 & - & 1734 & - & - & & - \\
\hline 14 & $71 \mathrm{M}$ & 3.0 & $14 \cdot 2$ & 100 & $4 \cdot 5$ & 29 & - & 154 & + & + & Cirrhosis & - \\
\hline 15 & $53 \mathrm{~F}$ & $2 \cdot 8$ & $13 \cdot 8$ & 96 & $5 \cdot 4$ & 272 & - & 287 & - & - & - & - \\
\hline 16 & $40 \mathrm{M}$ & $2 \cdot 8$ & 16.7 & 101 & $10 \cdot 1$ & 130 & - & 609 & - & - & - & - \\
\hline 17 & $47 \mathrm{M}$ & $2 \cdot 6$ & $11 \cdot 3$ & 88 & $8 \cdot 4$ & 618 & - & 553 & - & - & & - \\
\hline 18 & $52 \mathrm{~F}$ & $2 \cdot 5$ & $11 \cdot 1$ & 113 & $3 \cdot 5$ & 110 & TC & 900 & + & - & Cirrhosis & - \\
\hline
\end{tabular}

$\mathrm{MCV}=$ mean corpuscular volume; $\mathrm{WBC}=$ white blood count; $\mathrm{Plts}=$ platelets; $\mathrm{GGT}=$ gamma glutamyl transferase; $\mathrm{TC}=$ target cell.

excluded (coeliac disease, inflammatory bowel disease, thyrotoxicosis, rheumatoid arthritis and connective tissue diseases including systemic lupus erythematosus).

\section{ASSESSMENT OF SPLENIC FUNCTION}

Evidence for hyposplenism was sought from an examination of the peripheral blood film in each patient.

Splenic function was assessed by counting the number of erythrocyte indentations or pits using the method described by Corazza. ${ }^{6} \mathrm{~A}$ single drop of fresh blood was added to $0.5 \mathrm{ml} \mathrm{3 \%}$ glutaraldehyde at $\mathrm{pH} 7.4$ in a plastic tube and mixed. One drop of the erythrocyte preparation was examined under oil emersion using a Zeiss Axioskop microscope fitted for differential interference contrast microscopy, at a magnification of $\times 1000$. For each sample, 1000 erythrocytes were counted and the percentage of cells with one or more pits noted. Normal values are less than $2 \% .^{4}$ All samples were analysed by a single observer (AFM) without knowledge of the patients medical history.

\section{STATISTICAL ANALYSIS}

Wilcoxon's signed-rank test was used to compare results from the alcohol group with control subjects.

\section{Results}

There was no microbiological evidence of bacterial peritonitis in any of the 17 patients with abdominal ascites. Six patients had had previous infections and each of these was drinking heavily. Two (cases 5 and 7, Table) had pneumococcal infection (one with pneumonia and the other with pneumococcal septicaemia who subsequently died). These two patients, together with a third (case 3, Table) with sepsis from a klebsiella urinary tract infection had high pitted erythrocyte counts consistent with functional hyposplenism. Of the remaining three patients who had had infections but normal pitted cell counts, one had recently finished a course of treatment for pumonary tuberculosis and a fifth had culture negative pneumonia. The sixth patient was treated with broad spectrum parenteral antibiotics for a swinging pyrexia and leucocytosis after variceal sclerotherapy although all cultures were negative.

Nine patients had target cells on a blood film but none had evidence of Howell Jolly bodies. The mean (SEM) percentage of pits in the alcohol group was $2.7(0.4) \%$ and 18 patients had values greater than $2 \%$. Of these the blood film often revealed erythrocytes with multiple pits unlike in the control group where this was unusual. The percentage of red cells with pits or indentations in the control group was 0.7 $(0.07) \%$. This was significantly less than in the alcohol group $(\mathrm{p}<0.001)$. Figure 1 illustrates the spread of results for the alcoholics and the controls. The highest count in the alcohol group was $14.8 \%$ in a chronic alcoholic aged 49 years who had been drinking heavily since the age of 15 years. Figure 2 shows the blood film of the patient with the highest number of pits when viewed under differential interference contrast microscopy.

Of the 15 patients with biopsy proven alcohol induced cirrhosis, six had abnormal pitted erythrocyte counts. None of the reformed drinkers (five with biopsy proven cirrhosis), who had

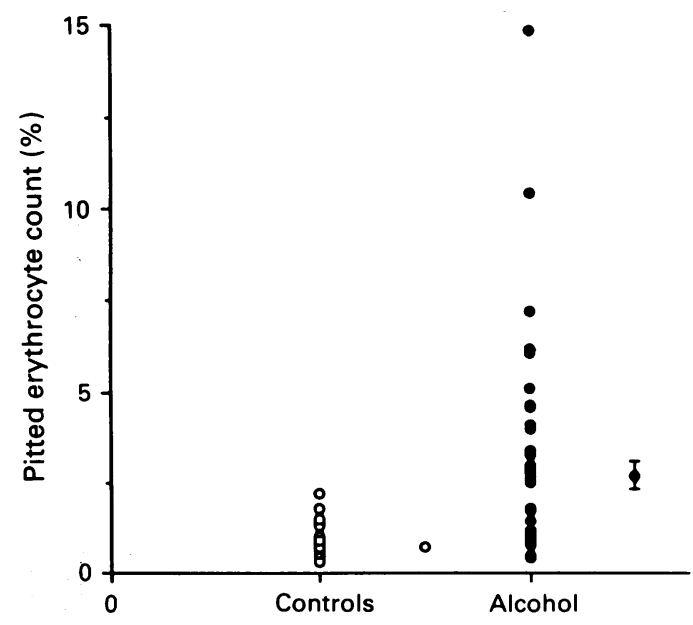

Figure 1: Percentage of pitted red cells in the alcoholics (O) and age and sex matched controls $(\bigcirc)$. Cell counts in the alcoholics were considerably higher than in the copitrols $(p<0.001)$. Eighteen of the patients were cons idered to have values above the upper limit of normal. 


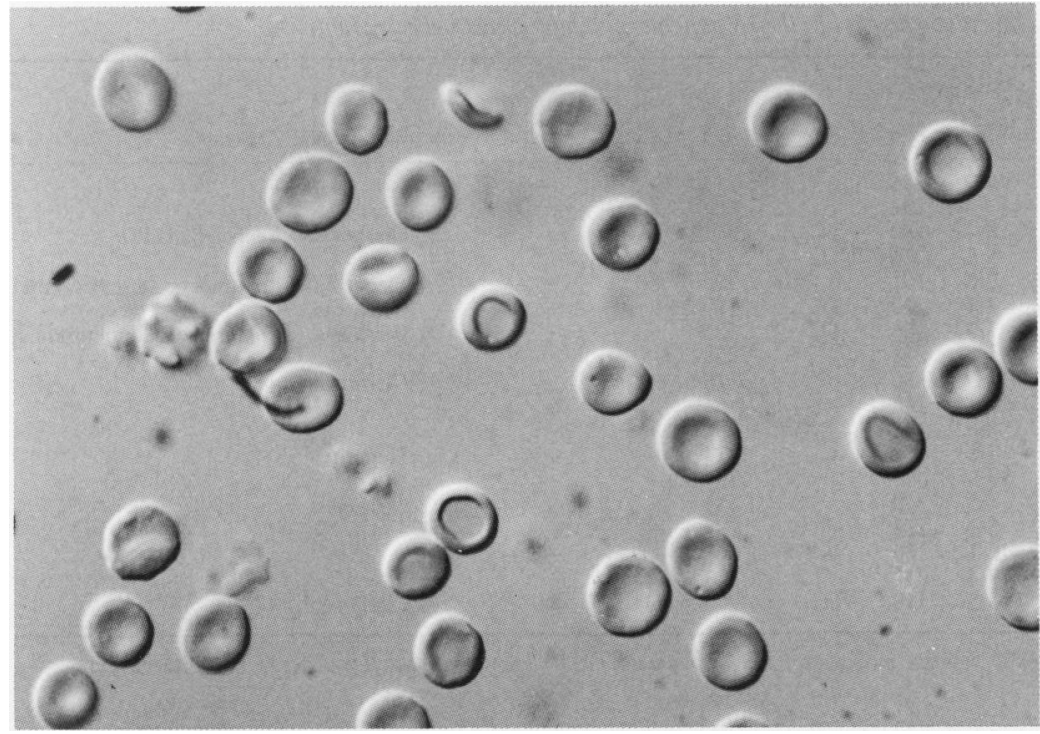

Figure 2: Blood film from the patient with the highest pitted erythrocyte count as viewed by differential contrast microscopy. This slide shows red cells with multiple pits, something that did not occur in the control group. megaly. This 'hypersplenic hyposplenism' suggested that in this group splenic function had little to do with spleen size. The haematopathological status of this group did not reliably differentiate them from the 'reformed drinkers'.

\section{Discussion}

Although only an indirect method of assessing splenic function, the measurement of pitted erythrocyte counts has been shown to correlate well with other measurements of splenic function, ${ }^{4}$ albeit in particular circumstances such as treated coeliac disease. ${ }^{6}$ While it does not necessarily imply that defective pitting is associated with defective immunological activity, using the technique of differential interference contrast microscopy, this study has highlighted the existence of functional hyposplenism in alcoholic liver disease and suggests that defective splenic function may be an additional mechanism involved in the susceptibility of this group of patients to infection.

The method that we have used to detect splenic hypofunction is linked to changes in the red cell membrane. This may be particularly important when one considers the potentially complex and multiple haematological abnormalities in alcoholic liver disease, including blood loss, macrocytosis, haemolysis, and sideroblastic change..$^{21}$ In patients with young cell populations, Holroyde and Gardner ${ }^{22}$ found more membrane indentations or pits in immature erythrocytes, particularly reticulocytes. Others have suggested that in patients with a high reticulocytosis there might be a backlog of new cells awaiting clearance and 'depitting' by the spleen, the so called 'overload syndrome' ${ }^{23}$ As heavy, active drinkers are more likely to have a faster turnover of erythrocytes than reformed drinkers this might be put forward as a reason why our reformed drinkers did not have high pitted red cell counts. Although we did not measure reticulocyte counts in our patients there was no evidence from the blood films of significant reticulocytosis or polychromasia and it seems unlikely that this explanation might have contributed to our results.

There are several possible explanations for the finding of functional hyposplenism in this group of patients with alcoholic liver disease. All the patients with high pitted cell counts were currently drinking and none of the eight reformed drinkers (five with biopsy proven cirrhosis) had abnormal counts. This points to a toxic effect of the alcohol itself. As yet, we do not have the evidence that long term abstinence improves splenic function.

An alternative explanation is that liver disease itself might be a major factor but we have not found high pitted red cell counts in patients with chronic active hepatitis or primary biliary cirrhosis (Muller and Toghill, unpublished observations). Spleen size may play a vital role but other reports have shown that this relates poorly with function ${ }^{36-18}$ and indeed two of the current series had palpable splenomegaly and functional ryposplenism. Portal hypertension may be important in determining the microcirculatory flow in the splenic pulp. Unfortunately, we do 
not know the precise site of the depitting process within the spleen. Traditionally it has been assumed that this is at the interendothelial slits where the red cells enter the venous sinuses from the reticuloendothelial meshwork. Portal hypertension with stasis and pooling of blood in the reticuloendothelial meshwork may interfere with this process. No single clear explanation emerges to explain the high pitted counts in alcoholic liver disease and it is likely to be multifactorial.

Wyke $^{20}$ has previously discussed why alcoholics get infections. Explanations for their increased susceptibility include the impairment of humoral and cellular host defences, defective reticuloendothelial phagocytic function and impaired complement activity. As in patients who have undergone splenectomy, alcoholics have a predisposition to pneumococcal infection $^{24}$ and two of the current group had had pneumococcal disease, (both with evidence of functional hyposplenism) with one dying from overwhelming septicaemia. The risk of postoperative infections in patients in which a diagnosis of alcoholic liver disease had not been established preoperatively had also been shown to be high. ${ }^{25}$ The Sheffield group ${ }^{3}$ has shown similar postoperative complications, together with disseminated intravascular coagulation in patients with inflammatory bowel disease undergoing surgery who were found to have defective splenic function as assessed by the clearance of heat damaged erythrocytes. Preoperative identification of such patients is important and any suspicion of infection with underlying hyposplenism should be promptly treated with parenteral antibiotics. Because of the high risk of Gram positive infections (unrelated to invasive procedures such as abdominal paracentesis) and in particular pneumococcal infection ${ }^{24}$ there may be an indication to give this group of patients pneumococcal vaccination. Previous work has shown that alcoholics were able to mount an adequate antibody response to pneumococcal polysaccharide antigen. ${ }^{26}$

This is the first reported study to show convincingly the presence of functional hyposplenism in patients with alcoholic liver disease. It seems highly likely that this contributes to their increased risk of infection.
We would like to thank Dr J E Freeman, Derby City Hospital, and Sister Bente Poole, Nottingham Clinic, for allowing me access to patients under their care.

1 Ryan FP, Smart RC, Preston FE, Holdsworth CD. Hyposplenism in ulcerative colitis. Lancet 1974; ii: 318-20.

2 Ryan FP, Ward AM, Holdsworth CD. Autoimmunity, inflammatory bowel disease and hyposplenism. Qf Med 1991; 78: $59-63$.

3 Ryan FP, Smart RC, Holdsworth CD, Preston FE. Hyposplenism in inflammatory bowel disease. Gut 1978; 19: 50-5.

4 Foster PN, Losowsky MS. Hyposplenism. In: Bowdler AJ. The Spleen - structure, function and clinical significance. London: Chapman and Hall, 1990: 232-59.

5 Marsh GW, Stewart JS. Splenic function in adult coeliac disease. Br F Haematol 1970; 19: 445-57.

6 Corazza GR, Bullen AW, Hall R, Robinson PJ, Losowsky MS. Simple method of assessing splenic function in coeliac disease. Clin Sci 1981; 60: 109-13.

7 Bullen AW, Hall R, Gowland G, Rajah S, Losowsky MS. Hyposplenism, adult coeliac disease and auto immunity. Gut 1980; $21: 28-33$.

8 Corazza GR, Gasbarrani G. Defective splenic function and its relation to bowel disease. Clin Gastroenterol 1983; 12: 65169.

9 Pearson HA, Spencer RP, Cornelius EA. Functional asplenia in sickle cell anaemia. $N$ Engl F Med 1969; 281: 923-6.

10 Neilan BA, Berney SN. Hyposplenism in systemic lupus erythematosus. F R heumatol 1983; 22: 176-8.

11 Brownlie BEW, Hamer JW, Cook HB, Hamwood SM. Thyrotoxicosis associated with splenic atrophy. Lancet 1975; ii: $1046-7$.

12 Gertz MA, Kyle RA, Griepp PR. Hyposplenism in primary systemic amyloidosis. Ann Intern Med 1983; 98: 475-7.

13 Markus $M H$, Toghill PJ. Impaired splenic function in elderly people. Age Aging 1991; 20: 287-90.

14 Marsh GW, Lewis SM, Szur L. The use of ${ }^{51} \mathrm{Cr}$-labelled heat damaged red cells to study splenic function. 1 . Evaluation of the method. Br F Haematol 1966; 12: 161-6.

15 Schnitzer B, Rucknagel DL, Spencer HH, Aikawa M. Erythrocytes: pits and vacuoles as seen with transmission and scanning electron microscopy. Science 1971;173: 251-2.

16 Palmer KR, Sherriff SB, Holdsworth CD. Changing pattern of splenic function in coeliac disease. Gut 1979; 20: A920.

17 Robinson PJ, Bullen AW, Hall R, Brown RC, Baxter P, Losowsky MS. Splenic size and function in adult coeliac Losowsky MS. Splenic size and functi

18 Smart RC, Ryan FP, Holdsworth CD, Preston FE. Relationship between splenic size and splenic function. Gut 1978; 19: 56-9.

19 Steinberg MH, Gatling RR, Tavassoli M. Evidence of hyposplenism in the presence of splenomegaly. Scand $\mathcal{F}$ Haematol 1983; 31: 437-9.

20 Wyke RJ. Problems of bacterial infection in patients with liver disease. Gut 1987; 28: 623-41.

21 Sherlock S. The haematology of liver disease. In: Diseases of the liver and biliary system. 8th ed. Oxford: Blackwell Scientific, 1989: 49-69.

22 Holroyde CP, Gardner FH. Acquisition of autophagic vacuoles by human erythrocytes: physiological role of the vacuoles by human erythrocy

23 Spencer RP, Pearson HA. Splenic radiocolloid uptake in the presence of circulating howell-jolly bodies. $\mathcal{f}$ Nucl Med 1974; 15: 294-5.

24 Austrian R, Gold J. Pneumococcal pneumonia with especial reference to bacteremic pneumococcal pneumonia. Ann Intern Med 1964; 60: 759-66.

25 Powell-Jackson P, Greenway B, Williams R. Adverse effects of exploratory laparotomy in patients with unsuspected liver disease. Br $₹$ Surg 1982; 69: 449-51.

26 Pirovino M, Lydick E, Grob PJ, Arrenbrecht S, Altorfer J, Schmid M. Pneumococcal vaccination: the response of patients with alcoholic liver cirrhosis. Hepatology 1984; 4: patients 